\title{
A First Step Towards Eliminating Malnutrition: A Proposal for Universal Nutrition Screening in Pediatric Practice
}

\author{
Robert D Murray' \\ Kirk W Kerr ${ }^{2}$ \\ Cory Brunton (D) ${ }^{2}$ \\ Jennifer A Williams $\mathbb{1 D}^{2}$ \\ Tiffany DeWitt ${ }^{2}$ \\ Karyn L Wulf ${ }^{2,3}$ \\ 'The Ohio State University College of \\ Medicine, Columbus, OH, USA; ${ }^{2}$ Abbott \\ Nutrition, Columbus, OH, USA; \\ ${ }^{3}$ Nationwide Children's Hospital Division \\ of Emergency Medicine, Columbus, \\ $\mathrm{OH}$, USA
}

This article was published in the following Dove Press journal: Nutrition and Dietary Supplements

Background: Childhood malnutrition remains far too common around the world today. In this paper, we discuss pediatric malnutrition in the context of protein-energy undernutrition and hidden hunger (single or multiple micronutrient deficiencies). Recent growth statistics show that nearly 150 million children under 5 years are stunted, and 50 million are wasted. At the same time, millions more children experience undernutrition of lesser severity but with negative effects on growth nonetheless. Beyond poor growth, such nutrient shortfalls can predispose children to impaired physical and mental development, which may have lifelong consequences. The World Health Organization recently set an aspirational goal "to end all forms of childhood malnutrition by 2030."

Plan of Action: Our paper proposes a stepwise strategy to raise awareness of childhood malnutrition risk and to work toward building a consensus on pediatric malnutrition screening as a pathway to ending childhood malnutrition. In a full plan for action, we propose to convene an expert Working Consensus Group on Pediatric Nutrition Screening (WCG-PNS). We propose that this group will work to (1) identify malnutrition screening tools specific for universal screening of children in hospital and community settings, (2) plan and lead healthcare professional training on how to screen for malnutrition risk, then take appropriate follow-up steps, (3) guide and advise quality improvement programs (QIPs) to facilitate incorporation of nutrition screening and interventions into everyday practice, and (4) measure and communicate potential findings in terms of health and financial outcomes.

Conclusion: We recognize an urgent need for universal screening of infants and children for nutritional risk-around the world and across the continuum of care. Such screening is expected to promote early identification of children who can benefit from nutrition interventions, then ensure that these children get needed nutritional support. In this way, we aim to prevent growth impairment, which has also been associated with adverse effects on mental and physical development.

Keywords: malnutrition, pediatrics, nutrition screening, nutritional interventions, undernutrition, clinical outcomes

\section{Introduction}

Childhood malnutrition is still far too common around the world today. As a triple threat, malnutrition presents in 3 forms - undernutrition, hidden hunger (micronutrient deficiencies), and overnutrition. ${ }^{1}$ Here we discuss pediatric malnutrition in the context of protein-energy undernutrition and hidden hunger (single or multiple micronutrient deficiencies). As undernutrition and hidden hunger, pediatric malnutrition is defined as an imbalance between nutrient needs and nutrient intake, which results in a cumulative
Correspondence: Karyn L Wulf Abbott Nutrition, 2900 Easton Square Place, Columbus, $\mathrm{OH}, 43219$, USA $\mathrm{Tel}+\mid$ 6|4-370-449|

Email Karyn.wulf@abbott.com

Nutrition and Dietary Supplements 2021:13 17-24 
deficit of energy, protein, or micronutrients. ${ }^{2}$ The consequences of such nutrient shortfalls can include poor growth and impaired physical or mental development. ${ }^{2-4}$ Despite global nutrition initiatives and steady progress over the past 2 decades, the number of children worldwide with poor growth as an indicator of poor nutrition remains disturbingly high. $^{1,5,6}$ In fact, recent growth statistics show nearly 150 million children under 5 years are stunted, and 50 million are wasted. ${ }^{5}$ At the same time, millions more children experience undernutrition of lesser severity but with negative effects on growth nonetheless. ${ }^{3}$ For example, a recent survey study found that about $2 \%$ of US children ages 1 to 13 years were moderately undernourished based on anthropometric data, while nearly $11 \%$ had evidence of mild undernutrition. $^{7}$

\section{Causes and Consequences of Childhood Malnutrition}

The causes of malnutrition in infants and children vary widely (Table 1). Pediatric malnutrition occurs in high-, middle-, and low-income countries alike, with some causes common to all and others very different. Eating and feeding disorders as well as poor diet quality cause malnutrition in children everywhere. ${ }^{8,9}$ Likewise, neurological abnormalities, specific diseases, and severe injuries put all infants and children at high risk of malnutrition, eg, gastrointestinal, heart, and kidney defects, cerebral palsy,

Table I Childhood Malnutrition: Causes, Mechanisms, Evidence Measures, and Treatments

\begin{tabular}{|l|l|}
\hline Category & - Acute or Chronic \\
& - Mild, Moderate or severe \\
\hline Cause & $\begin{array}{l}\text { - Socioeconomic, behavioral, or environmental } \\
\text { factors } \\
\text { - Disease, disability, or severe injury }\end{array}$ \\
\hline Mechanism & - Decreased nutrient intake or absorption \\
& Increased nutrient loss or nutrient needs \\
\hline Evidence & $\begin{array}{l}\text { - Underweight } \\
\text { - Low z-scores or growth percentiles } \\
\text { - Reduced dietary intake } \\
\text { - Physical findings }\end{array}$ \\
\hline Primary treatment & $\bullet$ Address underlying causes \\
\hline Nutritional & - Food fortification \\
treatment & $\begin{array}{l}\text { ONS } \\
\text { - Enteral feeding }\end{array}$ \\
\hline
\end{tabular}

cystic fibrosis, short bowel syndrome, solid tumor cancers, and third-degree burns. ${ }^{10-12}$ Factors not related to illness or injury also contribute to malnutrition risk. Some children worldwide may not eat enough healthy foods because their family cannot afford or lacks access to such foods, or because the family does not follow a diverse diet. ${ }^{13}$ Child abuse, neglect, and homelessness increase risk of malnutrition for children, even those living in high-income countries. ${ }^{14}$ For children in low- and middle-income countries, poor quality drinking water and inadequate sanitation can lead to gastrointestinal infections that impair nutrient absorption and cause chronic malnutrition. ${ }^{15,16}$

Inadequate nutrition early in life impairs growth in childhood and jeopardizes a child's likelihood of reaching full linear growth potential. ${ }^{6,17-23}$ A poor nutritional start can also predispose a child to health problems from early childhood through adulthood. Malnutrition makes children more susceptible to infections, and severe malnutrition increases risk of death. ${ }^{24,25}$ Disability-adjusted life years (DALYs) - a measure of overall disease burden expressed as the number of years lost due to ill-health, disability, or early death —are elevated by childhood malnutrition. ${ }^{26}$ Developmental delays caused by early undernutrition can affect cognitive outcomes and impair productive potential as adults. ${ }^{27}$ Taken together, impaired physical growth and cognitive ability can lead to loss of future productivity, also called "loss of human capital." 28 As well, evidence links early childhood growth failure with increased risk factors for cardiovascular disease in later life, including dyslipidemia, hypertension, and glucose intolerance. ${ }^{29}$

\section{Addressing Childhood Malnutrition}

Importantly, risk for malnutrition can be identified, preferably as early as possible, in order to take corrective actions (Table 1). Risk of malnutrition can be identified by use of simple, validated tools. When risk is identified, full nutritional assessments are used to determine underlying problems and to characterize the severity of malnutrition. Treatments involve addressing malnutrition causes when possible and providing nutritional interventions to reverse deficiencies. Our current paper proposes a stepwise strategy to raise awareness of childhood malnutrition risk and to work toward building consensus on pediatric malnutrition screening. We propose a comprehensive strategy to:

- identify malnutrition screening tools specific for universal screening of children in hospital and community settings, 
- plan and lead healthcare professional training on how to screen for malnutrition risk, then take appropriate follow-up steps,

- conduct quality improvement programs (QIPs) to facilitate incorporation of nutrition screening and interventions into everyday practice, and

- measure and communicate potential benefits in terms of health and financial outcomes.

\section{Taking Action}

\section{Big-Picture Goals for the 2 Ist Century}

In 2012, the World Health Assembly (WHA) endorsed a comprehensive plan to improve nutrition in mothers, infants, and young children. ${ }^{30}$ In the plan, a key goal was to reduce stunting and wasting in children; the specific global target was to reduce by $40 \%$ the number of stunted under-five children by $2025 .{ }^{31}$ When WHO updated the plan 5 years later, the new aspirational goal was to end all forms of childhood malnutrition by $20300^{32}$

In the 21st Century, severe malnutrition with growth impairment has in fact trended downward. ${ }^{5,33}$ For example, middle-income countries have had significant declines in the number of stunted children; countries like Bolivia and China halved rates of child undernourishment since $1990 .^{34}$ As emphasized by global nutrition leaders, further efforts are needed to sustain and extend these trends to reach the ultimate aim for "all children to be free of malnutrition in all forms.",33

\section{A Proposal to Fill Gaps in Pediatric Nutrition Care}

Improving children's nutrition requires effective and sustained multi-sector nutrition programming over the long term. To this end, our call-to-action proposes specific steps toward filling gaps in pediatric nutrition practice (Figure 1). Screening for nutritional risk in pediatric populations is a major gap and a primary goal to fill. It is optimal to recognize undernutrition risk and to implement nutritional interventions long before wasting and stunting actually occur. When children are found to be at risk for malnutrition, a cascade of events should occur-full nutritional assessment for diagnosis of undernutrition or malnutrition, followed by specific recommendations for nutritional care (dietary counseling and specific nutrition care) as needed. To implement such steps, hospitals, clinics, and pediatric practices need to develop protocols that ensure all children are screened for nutrition risks on hospital

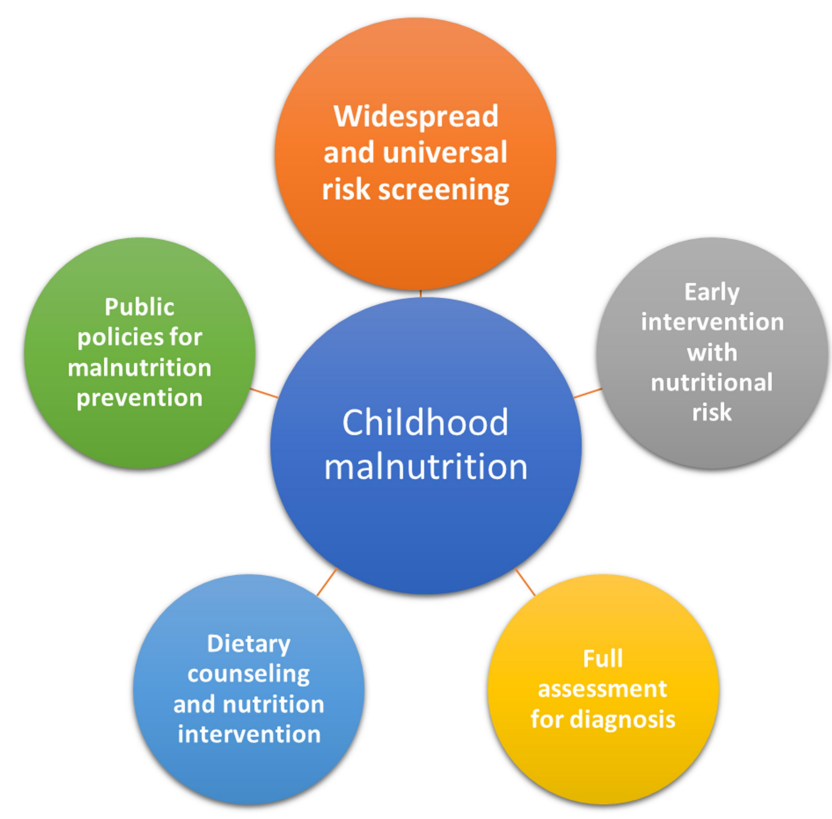

Figure I Filling gaps in pediatric nutrition practice to reduce growth stunting, wasting, and other adverse outcomes of malnutrition.

admission and at each healthcare visit in the community. Such practices can be encouraged by country-wide policies on nutrition-focused healthcare for children and supported by regional and local practice standards. We further encourage regular data collection in order to monitor and analyze progress toward malnutrition risk screening and follow-up goals.

\section{Specific Gaps to Be Addressed in Updated Pediatric Nutrition Care}

Simply stated, our primary goal is to achieve universal nutrition screening, ie, routine use of screening across the continuum of pediatric care.

(a) Hospitalized patients: Validated tools are available, but we aim to achieve consensus on selection of a single tool; such consistency will allow comparison of data across sites and settings.

(b) Outpatient settings: Incorporate routine screening into practice; validation studies for screening tools and as for inpatients, we need consensus-based selection of a screening tool and training for its standardized use.

(c) Ultimately, we aim to spread nutrition screening beyond hospital and clinical settings; reaching children in the community will help meet the 2030 WHO goal to end all forms of childhood malnutrition by $2030 .^{32}$ 


\section{Putting Nutrition Screening into Practice: How to Do It}

Nutrition screening is used for identification of risk for malnutrition or change in risk for malnutrition. A traditional approach to evaluate a child's nutritional adequacy has been to compare a child's growth measures with those of a standard population. The World Health Organization (WHO) has a full set of childhood growth standards by age and sex. ${ }^{35}$ WHO characterizes growth in terms of z-scores - the number of standard deviations from the median value of the comparable WHO reference population. ${ }^{35,36} \mathrm{~A} z$-score between -1 and -2 indicates the child has evidence of mildly poor growth and may be at risk for undernutrition; a z-score between -2 and -3 indicates moderate undernutrition and $<-3$ signifies severe undernutrition. ${ }^{2}$ Stunting is defined as height-forage $\mathrm{z}$-score $(\mathrm{HAZ})<-2$, wasting as weight-for-height $\mathrm{Z}$-score $(\mathrm{WHZ})<-2$, and underweight as weight-for-age $z$-score $(W A Z)<-2$. These cut-off values are based on the concept that the middle $95 \%$ of the statistical distribution represents the normal range, which is within two standard deviations above or below the median (z-score between -2 and +2$)$. Similarly, growth parameters can be expressed in terms of percentiles (HAP, WHP, WAP); z-scores of -2 and -1 are approximately equivalent to the 2 nd and 15 th percentiles. Body Mass Index (BMI)-for-age and midupper arm circumference-for-age-are also advised by WHO as growth and nutrition indicators. ${ }^{35}$ Finally, use of mid-upper arm circumference and skinfold thickness can be used as further indicators of nutritional status. ${ }^{4,34,35}$

\section{Selecting a Pediatric Nutrition Screening Tool}

While anthropometric measures are a widely used proxy for nutritional status in infants and children, such measures can be more time-consuming than simple screening questionnaires, which are commonly used for adults. ${ }^{37}$ In response to this gap, over 14 pediatric malnutrition screening tools have been described in the literature as well as several different review papers. For example, a recent systematic review by Becker et al compared validity and reliability and identified 3 pediatric nutrition screening tools with moderate-to-high validity and reliability for screening hospital inpatients $^{38}$ Screening Tool for the Assessment of Malnutrition in Pediatrics (STAMP), ${ }^{39}$ Screening Tool for Risk of Impaired Nutritional Status and Growth (STRONGkids), ${ }^{40}$ and the Paediatric Yorkhill Malnutrition
Score (PYMS). ${ }^{41}$ Another validated inpatient screening tool developed by nurses and dietitians in Australia for use in hospitals, the Pediatric Nutrition Screening Tool (PNST) has been recommended by some for its simplicity and ease of use. ${ }^{42}$ These 4 tools are compared in Table 2. It is important to note, that different reviews comparing pediatric screening tools have led to differing conclusions. This lack of clarity on which screening tool to use may be one of the obstacles to implementing universal malnutrition screening in the inpatient setting.

\section{What is the Best Screening Tool for Hospitals? For Healthcare in the Community?}

Notably, all 4 of the validated pediatric tools were developed for use in inpatients. But an important gap in current pediatric nutrition screening is that use of different tools

Table 2 Pediatric Nutrition Screening Tools: Questions

\begin{tabular}{|c|c|}
\hline Screening Tool & Questions \\
\hline STAMP & $\begin{array}{l}\text { I. Does the child have a medical condition that } \\
\text { affects his or her nutritional status? Definite, } \\
\text { possible, or no impact? } \\
\text { 2. What is the child's nutrition intake? None, } \\
\text { decreased, or normal? } \\
\text { 3. Is the child's weight-for-height proportional? } \\
\text { Scoring is based on BMl percentile chart. }\end{array}$ \\
\hline STRONGkids & $\begin{array}{l}\text { I. Is the child in poor nutritional status? } \\
\text { 2. Is there an underlying illness with a risk of } \\
\text { malnutrition or expected major surgery? } \\
\text { 3. Has the child had excessive diarrhea or vomit- } \\
\text { ing in the past week? } \\
\text { 4. Has the child had a significant reduction in } \\
\text { food intake recently? } \\
\text { 5. Has the child had weight loss or poor growth? }\end{array}$ \\
\hline PYMS & $\begin{array}{l}\text { I. Is the BMI below the cut-off value in the table } \\
\text { (chart provided)? Yes/no } \\
\text { 2. Has the child lost weight? Yes/no } \\
\text { 3. Has the child had reduced intake? Yes/no } \\
\text { 4. Will the child's nutrition be affected by the recent } \\
\text { admission/illness for at least the next week? Yes/ } \\
\text { no }\end{array}$ \\
\hline PNST & $\begin{array}{l}\text { I. Has the child had unintentional weight loss? } \\
\text { 2. Has the child had poor weight gain over the } \\
\text { past few months? } \\
\text { 3. Has the child been eating less than usual over } \\
\text { the past few weeks? } \\
\text { 4. Is the child visibly underweight? }\end{array}$ \\
\hline
\end{tabular}


limits our ability to compare site-to-site findings on malnutrition prevalence and follow-up practice. Further, there is no pediatric screening tool yet validated for use in community clinics and pediatric practices, another major gap that needs to be filled. Screening in the outpatient setting may need to consider food insecurity and diet diversity as well as hidden hunger (micronutrient deficiencies in the setting of normal or above weight-for-height), and this may necessitate variation to current inpatient screening tools. If we do not have an agreed-upon screening tool for use in outpatient settings, we are missing many early opportunities to identify children at risk of malnutrition.

\section{Other Gaps Related to Nutrition Screening in Pediatric Practice: Training and Policy Development}

Two other major gaps exist for achieving universal pediatric nutrition screening. First of all, once screening tools are selected, it is necessary to provide training materials and practice for correct use of the screening tools. If frontline providers are not fully trained, we miss opportunities for interventions. Secondly, to underscore the importance using these tools, it will be critical for countries, regional, and local health authorities to develop policies and protocols, and gain alignment of pediatric and nutrition societies to support incorporation of screening tools into pediatric practice.

\section{Why Addressing Childhood Nutrition Matters: Health and Economic Impact}

There are many lessons that can be learned from adult healthcare practices of nutrition screening and care. Malnutrition can be viewed as an independent disease state and treated as one too; malnutrition has been shown to worsen clinical outcomes and to increase morbidity, mortality, and complication rates, thus causing additional costs. ${ }^{43}$ On the other hand, there is ample evidence that nutrition screening identifies more patients at risk of malnutrition, allows faster implementation of interventions, and improves patient outcomes. With such improvements, there is much evidence to show that malnutrition treatment lowers healthcare resource utilization and cuts costs. ${ }^{44-52}$ In comparison, relatively few studies have explored comparable benefits of pediatric nutrition interventions. One recent publication demonstrated pediatric patients at high nutritional risk were found to have hospital stays that were
16 days longer and $\$ 3500$ more expensive than patients at moderate nutritional risk. ${ }^{53}$ Other early findings suggest that similar results will follow for pediatric care ${ }^{53-57}$ These early pediatric studies build justification for screening: immediate cost-to-benefit return, not only in terms of health care costs, but also morbidity and mortality and patient quality of life.

Beyond the immediate short-term costs, if malnutrition in early childhood goes untreated, there can be serious tolls on human capital, evidenced by slower cognitive development, reduced schooling attainment, and decreased adult incomes by 5 to $53 \% .{ }^{58}$ On the other hand, prevention of undernutrition offers opportunities to preserve human capital, which is expected to translate as a returnon-investment by bettering economic productivity. By focusing on widespread and universal screening for malnutrition risk in hospitals and communities worldwide, we aim to detect and treat nutritional risk before it worsens.

\section{A Plan for Action on Pediatric Nutrition Screening}

As a plan for action to improve pediatric nutrition practice, we propose to convene an expert Working Consensus Group on Pediatric Nutrition Screening (WCG-PNS). Specific goals for this Working Consensus Group would be to focus on filling 5 key gaps (Figure 2):

- Identify a validated PNS Tool for universal screening of hospital inpatients and identify a validated PNS tool for universal screening of outpatients visiting community clinics and pediatric practices. Engage key pediatric and nutrition society partners to develop and publish practice guidelines.

- Design PNS Support Kits to facilitate nutrition awareness, training, and care in practice (eg, a glossary of nutrition-related terms, checklists for nutrition-related history-taking, education and training for taking anthropometric measures and interpreting them, training for effective and efficient use of nutritional screening, and guidance on follow-up nutritional intervention). The corollary to screening will be instituting nutritional intervention guidelines based on expert recommendations. This will be the key to establishing a new standard of care for at-risk children and teens.

- Build multi-disciplinary groups of medical professionals for education and training on use of PNS Tools and Support Kits; such groups include 


\section{Convene an expert Working Consensus Group (WCG) \\ on Pediatric Nutrition Screening (PNS)}

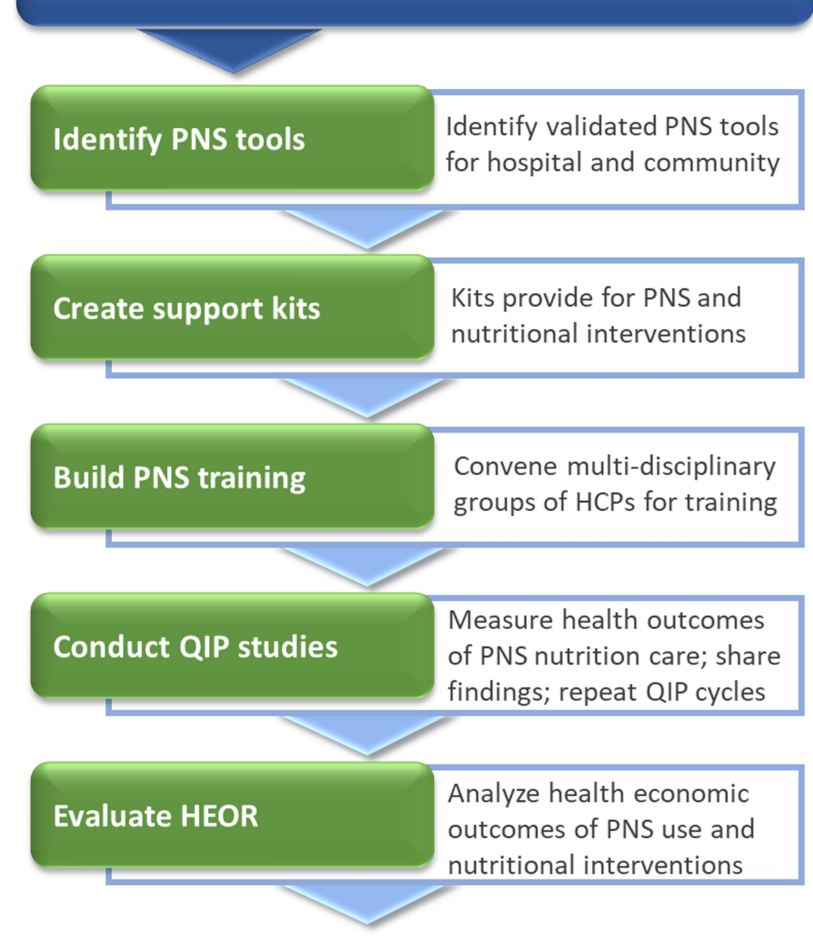

Successfully identifying and treating

malnutrition in infants and children can

improve growth and other health outcomes.

Figure 2 Action plan to enhance Pediatric Nutrition Screening, facilitate treatment, and improve health and economic outcomes.

Abbreviations: HCPs, healthcare professionals; QIP, quality improvement program; HEOR, health economic outcomes research.

physicians, nurses, and dietitians in hospitals, clinics, and community practices.

- Measure outcomes of improved PNS by designing nutrition-focused quality improvement programs (QIPs), including strategies for data collection and analysis. Conduct QIP studies, analyze and share findings, and repeat steps in small "plan-do-studyact" iterative cycles for continued QIP on PNS.

- Based on outcomes data from pediatric nutrition screening initiatives, conduct health economic studies that can help inform potential savings derived from healthcare resource utilization and evaluate the long-term impact of nutrition screening and intervention on increasing productivity and preserving human capital. Potential sources for saving are lowered frequency of clinical visits, shortened hospital length of stays, and fewer hospital readmissions.

\section{Conclusions}

We recognize an urgent need for universal screening of infants and children for nutritional risk - around the world and across the continuum of care. Such screening is expected to promote early identification of children at nutritional risk who can benefit from nutrition interventions, then ensure that these children get needed nutritional support. In this way, we aim to prevent growth impairment, which can be associated with adverse effects on mental and physical development. To this end, we propose to convene an international Working Consensus Group on Pediatric Nutrition Screening.

\section{Data Sharing Statement}

Not applicable.

\section{Ethics Approval and Consent to Participate}

Not applicable

\section{Author Contributions}

All authors made a significant contribution to the work reported, whether that is in the conception, study design, execution, acquisition of data, analysis and interpretation, or in all these areas; took part in drafting, revising or critically reviewing the article; gave final approval of the version to be published; have agreed on the journal to which the article has been submitted; and agree to be accountable for all aspects of the work.

\section{Funding}

There was no funding for this paper.

\section{Disclosure}

Dr Robert D Murray serves in the Speaker's Bureau and provides consultation to Abbott Nutrition International. He was Professor of Pediatrics at The Ohio State University College of Medicine. Dr Kirk W Kerr, Mr Cory Brunton, Ms Jennifer A Williams, Ms Tiffany DeWitt, Dr Karyn L Wulf are employees and may be stockholders for Abbott Laboratories. The authors declare that they have no other competing interests in this work.

\section{References}

1. Mwangome M, Prentice AM. Tackling the triple threats of childhood malnutrition. BMC Med. 2019;17(1):210. doi:10.1186/s12916-019$1464-9$ 
2. Mehta NM, Corkins MR, Lyman B, et al. Defining pediatric malnutrition: a paradigm shift toward etiology-related definitions. JPEN J Parenter Enteral Nutr. 2013;37(4):460-481. doi:10.1177/0148607113479972

3. Bouma S. Diagnosing pediatric malnutrition. Nutr Clin Pract. 2017;32(1):52-67. doi:10.1177/0884533616671861

4. Becker PJ, Nieman Carney L, Corkins MR, et al. Consensus statement of the academy of nutrition and dietetics/american society for parenteral and enteral nutrition: indicators recommended for the identification and documentation of pediatric malnutrition (undernutrition). $J$ Acad Nutr Diet. 2014;114(12):1988-2000. doi:10.1016/j.jand.2014.08.026

5. United Nations Children's Fund (UNICEF) WHO, International Bank for Reconstruction and Development/The World Bank. Levels and Trends in Child Malnutrition: Key Findings of the 2019 Edition of the Joint Child Malnutrition Estimates. Washington DC: United Nations Children's Fund (UNICEF), World Health Organization, International Bank for Reconstruction and Development/The World Bank; 2019.

6. de Onis M, Branca F. Childhood stunting: a global perspective. Matern Child Nutr. 2016;12(Suppl 1):12-26.

7. Price A, Williams J, Doetsch H, Spees C, Taylor C. Utilization of current diagnostic indicators to characterize pediatric undernutrition among US children. Nutrients. 2020.

8. Tolia V. Very early onset nonorganic failure to thrive in infants. J Pediatr Gastroenterol Nutr. 1995;20(1):73-80.

9. Woolston JL. Eating disorders in infancy and early childhood. J Am Acad Child Psychiatry. 1983;22(2):114-121.

10. Joosten KF, Hulst JM. Prevalence of malnutrition in pediatric hospital patients. Curr Opin Pediatr. 2008;20(5):590-596. doi:10.1097/ MOP.0b013e32830c6ede

11. Kleinert JO. Pediatric feeding disorders and severe developmental disabilities. Semin Speech Lang. 2017;38(2):116-125. doi:10.1055/ s-0037-1599109

12. Romano C, Dipasquale V, Gottrand F, Sullivan PB. Gastrointestinal and nutritional issues in children with neurological disability. Dev Med Child Neurol. 2018;60(9):892-896. doi:10.1111/dmcn.13921

13. UNICEF. The State of the World's Children 2019. Children, Food and Nutrition: Growing Well in a Changing World. New York: United Nations Children's Fund (UNICEF); 2019.

14. Scharf RJ, Rogawski ET, Murray-Kolb LE, et al. Early childhood growth and cognitive outcomes: findings from the MAL-ED study. Matern Child Nutr. 2018;14(3):e12584. doi:10.1111/mcn.12584

15. Luby SP, Rahman M, Arnold BF, et al. Effects of water quality, sanitation, handwashing, and nutritional interventions on diarrhoea and child growth in rural Bangladesh: a cluster randomised controlled trial. Lancet Glob Health. 2018;6(3):e302-e315. doi:10.1016/S2214109X(17)30490-4

16. Tickell KD, Atlas HE, Walson JL. Environmental enteric dysfunction: a review of potential mechanisms, consequences and management strategies. BMC Med. 2019;17(1):181. doi:10.1186/ s12916-019-1417-3

17. UNICEF. Progress for children: a report card on nutrition. A report card on nutrition: number 4, May 2006; 2006. Available from: https:// www.unicef.org/progressforchildren/2006n4/index_undernutrition. html. Accessed November 14, 2019.

18. Nassar MF, Shaaban SY, Nassar JF, Younis NT, Abdel-Mobdy AE. Language skills and intelligence quotient of protein energy malnutrition survivors. J Trop Pediatr. 2012;58(3):226-230. doi:10.1093/tropej/fmr081

19. Sandjaja PBK, Rojroonwasinkul N, et al. Relationship between anthropometric indicators and cognitive performance in Southeast Asian school-aged children. Br J Nutr. 2013;110(Suppl 3):S57-64. doi:10.1017/S0007114513002079

20. Perignon M, Fiorentino M, Kuong K, et al. Stunting, poor iron status and parasite infection are significant risk factors for lower cognitive performance in Cambodian school-aged children. PLoS One. 2014;9 (11):e112605. doi:10.1371/journal.pone.0112605
21. Prentice AM, Ward KA, Goldberg GR, et al. Critical windows for nutritional interventions against stunting. Am J Clin Nutr. 2013;97 (5):911-918. doi:10.3945/ajcn.112.052332

22. Sudfeld CR, McCoy DC, Fink G, et al. Malnutrition and its determinants are associated with suboptimal cognitive, communication, and motor development in Tanzanian children. J Nutr. 2015;145 (12):2705-2714. doi:10.3945/jn.115.215996

23. Xie W, Jensen SKG, Wade M, et al. Growth faltering is associated with altered brain functional connectivity and cognitive outcomes in urban Bangladeshi children exposed to early adversity. BMC Med. 2019;17(1):199. doi:10.1186/s12916-019-1431-5

24. Walson JL, Berkley JA. The impact of malnutrition on childhood infections. Curr Opin Infect Dis. 2018;31(3):231-236. doi:10.1097/ QCO.0000000000000448

25. Nalwanga D, Musiime V, Kizito S, et al. Mortality among children under five years admitted for routine care of severe acute malnutrition: a prospective cohort study from Kampala, Uganda. $B M C$ Pediatr. 2020;20(1):182.

26. Black RE, Allen LH, Bhutta ZA, et al. Maternal and child undernutrition: global and regional exposures and health consequences. Lancet. 2008;371 (9608):243-260. doi:10.1016/S0140-6736(07)61690-0

27. Independent Evaluation Group for Communication Strategy and Learning. What Can We Learn from Nutrition Impact Evaluations? Lessons from a Review of Interventions to Reduce Childhood Malnutrition Oin Developing Countries. Washington, DC: The International Bank for Reconstruction and Development/The World Bank; 2010.

28. Victora CG, Adair L, Fall C, et al. Maternal and child undernutrition: consequences for adult health and human capital. Lancet. 2008;371 (9609):340-357. doi:10.1016/S0140-6736(07)61692-4

29. DeBoer MD, Lima AA, Oria RB, et al. Early childhood growth failure and the developmental origins of adult disease: do enteric infections and malnutrition increase risk for the metabolic syndrome?. Nutr Rev. 2012;70(11):642-653.

30. de Onis M, Dewey KG, Borghi E, et al. The World Health Organization's global target for reducing childhood stunting by 2025: rationale and proposed actions. Matern Child Nutr. 2013;9 (Suppl 2):6-26. doi:10.1111/mcn.12075

31. WHO. WHO Global Targets 2025. WHO (World Health Organization); 2012.

32. WHO. The extension of the 2025 maternal, infant and young child nutrition targets to 2030. WHO/UNICEF Discussion paper; 2017. Available from: https://www.who.int/nutrition/global-target-2025/discussion-paperextension-targets-2030.pdf. Accessed November 21, 2019.

33. United Nations Children's Fund (UNICEF) WHO, International Bank for Reconstruction and Development/The World Bank. Levels and Trends in Child Malnutrition: Key Findings of the 2018 Edition of the Joint Child Malnutrition Estimates. Geneva: United Nations Children's Fund (UNICEF), World Health Organization, International Bank for Reconstruction and Development/The World Bank; 2018.

34. Humger and undernourishment. OurWorldInData.org; 2020. Available from: 'https://ourworldindata.org/hunger-andundernourishment. Accessed May 15, 2020.

35. WHO. The WHO child growth standards; 2020. Available from: https:// www.who.int/childgrowth/standards/en/. Accessed April 25, 2020.

36. WHO. The Z-score or standard deviation classification system. Global Database on Child Growth and Malnutrition; 2019. Available from: https://www.who.int/nutgrowthdb/about/introduc tion/en/index4.html. Accessed April 23, 2020.

37. Ferguson M, Capra S, Bauer J, Banks M. Development of a valid and reliable malnutrition screening tool for adult acute hospital patients. Nutrition. 1999;15(6):458-464. doi:10.1016/S0899-9007(99)00084-2

38. Becker PJ, Gunnell Bellini S, Wong Vega M, et al. Validity and reliability of pediatric nutrition screening tools for hospital, outpatient, and community settings: a 2018 evidence analysis center systematic review. J Acad Nutr Diet. 2020;120(2):288-318 e282. doi:10.1016/j.jand.2019.06.257 
39. McCarthy H, Dixon M, Crabtree I, Eaton-Evans MJ, McNulty H. The development and evaluation of the Screening Tool for the Assessment of Malnutrition in Paediatrics (STAMPC) for use by healthcare staff. J Hum Nutr Diet. 2012;25(4):311-318. doi:10.11 11/j.1365-277X.2012.01234.x

40. Huysentruyt K, Alliet P, Muyshont L, et al. The STRONGkids nutritional screening tool in hospitalized children: A validation study. Nutrition. 2013;29(11-12):1356-1361. doi:10.1016/j.nut.2013.05.008

41. Gerasimidis K, Keane O, Macleod I, Flynn DM, Wright CM. A four-stage evaluation of the paediatric yorkhill malnutrition score in a tertiary paediatric hospital and a district general hospital. Br J Nutr. 2010;104(5):751-756. doi:10.1017/S0007114510001121

42. White M, Lawson K, Ramsey R, et al. Simple nutrition screening tool for pediatric inpatients. JPEN J Parenter Enteral Nutr. 2016;40 (3):392-398. doi:10.1177/0148607114544321

43. Norman K, Pichard C, Lochs H, Pirlich M. Prognostic impact of disease-related malnutrition. Clin Nutr. 2008;27(1):5-15. doi:10.10 16/j.clnu.2007.10.007

44. Elia M, Normand C, Laviano A, Norman K. A systematic review of the cost and cost effectiveness of using standard oral nutritional supplements in community and care home settings. Clin Nutr. 2016;35(1):125-137. doi:10.1016/j.clnu.2015.07.012

45. Elia M, Normand C, Norman K, Laviano A. A systematic review of the cost and cost effectiveness of using standard oral nutritional supplements in the hospital setting. Clin Nutr. Apr 2016;35 (2):370-380.

46. Philipson TJ, Snider JT, Lakdawalla DN, Stryckman B, Goldman DP. Impact of oral nutritional supplementation on hospital outcomes. Am J Manag Care. 2013;19(2):121-128.

47. Siegel S, Fan L, Goldman A, Higgins J, Goates S, Partridge J. Impact of nutrition-focused quality improvement on length of stay. $J$ Nutr Care Qual. 2019;34(3):203-209.

48. Sriram K, Sulo S, VanDerBosch G, et al. Nutrition-focused quality improvement program results in significant readmission and length of stay reductions for malnourished surgical patients. JPEN J Parenter Enteral Nutr. 2018;42(6):1093-1098. doi:10.1002/jpen.1040

49. Sriram K, Sulo S, VanDerBosch G, et al. A comprehensive nutrition-focused quality improvement program reduces 30-day readmissions and length of stay in hospitalized patients. JPEN J Parenter Enteral Nutr. 2017;41(3):384-391. doi:10.1177/0148607116681468
50. Sulo S, Feldstein J, Partridge J, Schwander B, Sriram K, Summerfelt WT. Budget impact of a comprehensive nutrition-focused quality improvement program for malnourished hospitalized patients.. Am Health Drug Benefits. 2017;10(5):262-270.

51. Tyler R, Barrocas A, Guenter P, et al. Value of nutrition support therapy: impact on clinical and economic outcomes in the United States. JPEN J Parenter Enteral Nutr. 2020;44(3):395-406. doi:10. 1002/jpen. 1768

52. Meehan A, Loose C, Bell J, Partridge J, Nelson J, Goates S. Health system Quality Improvement: impact of prompt nutrition care on patient outcomes and health care costs. J Nurs Care Qual. 2016;31 (3):217-223. doi:10.1097/NCQ.0000000000000177

53. Gambra-Arzoz M, Alonso-Cadenas JA, Jiménez-Legido $M$, et al. Nutrition risk in hospitalized pediatric patients: higher complication rate and higher costs related to malnutrition. Nutr Clin Pract. 2020;35 (1):157-163. doi:10.1002/ncp.10316

54. Dempster R, Burdo-Hartman W, Halpin E, Williams C. Estimated cost-effectiveness of intensive interdisciplinary behavioral treatment for increasing oral intake in children with feeding difficulties. J Pediatric Psychol. 2016;41(8):857-866. doi:10.1093/jpepsy/jsv112

55. Klek S, Hermanowicz A, Dziwiszek G, et al. Home enteral nutrition reduces complications, length of stay, and health care costs: results from a multicenter study. Am J Clin Nutr. 2014;100(2):609-615. doi:10.3945/ajen.113.082842

56. Lakdawalla DN, Mascarenhas $\mathrm{M}$, Jena $\mathrm{AB}$, et al. Impact of oral nutrition supplements on hospital outcomes in pediatric patients. JPEN J Parenter Enteral Nutr. 2014;38(2Suppl):42S-49S.

57. Phillips CA, Bailer J, Foster E, et al. Evaluation of an automated pediatric malnutrition screen using anthropometric measurements in the electronic health record: a quality improvement initiative. Support Care Cancer. 2020;28(4):1659-1666.

58. Shekar M, Kakietek J, D'Alimonte MR, et al. Reaching the global target to reduce stunting: an investment framework. Health Policy Plan. 2017;32(5):657-668.
Nutrition and Dietary Supplements

\section{Publish your work in this journal}

Nutrition and Dietary. Supplements is an international, peerreviewed, open access journal focusing on research into nutritional requirements in health and disease, impact on metabolism and the identification and optimal use of dietary strategies and supplements necessary for normal growth and development. The journal welcomes submitted papers covering original research, basic science,

\section{Dovepress}

clinical \& epidemiological studies, reviews and evaluations, guidelines, expert opinion and commentary, case reports and extended reports. The manuscript management system is completely online and includes a very quick and fair peer-review system, which is all easy to use. Visit http://www.dovepress.com/testimonials.php to read real quotes from published authors. 